\title{
Factors Affecting Financing of Rural Agricultural Projects in Rwanda: Experience of Equity Bank
}

\author{
Mukandoli Kayijamahe Chantal \\ Master of Business Administration in Project Management Option of the University of Kigali
}

\begin{abstract}
In the processes of financial deepening in low-income countries, lags prevail in the provision of services in the rural areas, particularly in the supply of the financial services required for agricultural activities and of those demanded by households that earn an important portion of their incomes from crops. This study examined factors affecting financing of rural agricultural projects in Rwanda with a focus on the experience of Equity Bank. Objectives were to assess how nature of existing financial products by Equity Bank influences financing of rural agricultural project in Rwanda; to examine how nature of rural agricultural projects in Rwanda influence access to Equity Bank's financial services; to assess how characteristics of rural clients who engage in agricultural projects in Rwanda influence their ability to access Equity Bank's financial services; and to examine influence of how rural agricultural environment in Rwanda influences ability of farmers to access Equity Bank's financial services. Results revealed that there was a positive and significant relationship between factors influencing financial support and rural agricultural projects ( $\mathrm{rho}=0.392$, $\mathrm{p}$ value $<0.05)$. Secondly, there was a positive significant relationship between financial services and farmers' progress (rho $=0.358, \mathrm{p}$ value $<0.05$ ). Thirdly, there was a positive and significant relationship between farmers' ability to access funds and rural agricultural projects (rho $=0.562, \mathrm{p}$ value $<0.05$ ). The research concluded equity bank to creates a strong coordination with rural farmers that indicated by the factor that the big number of respondents agree with the statements relate to successful projects. From on the shortcomings of the research, Equity bank is suggested to provide financial support whenever its necessary because a number of respondents disagreed with this statement and the rural agricultural projects leaders are suggested to rely most of the time on the financial institutions.
\end{abstract}

Key words rural agricultural projects, Financing Factors

\section{Introduction}

In the past two decades there has been a rapid growth in the global demand for agricultural products, mainly due to a growing global population and a rise in the purchasing power of people living in developing countries (Hernández, 2017). Globally, the supply of agricultural products has responded effectively to this growth in demand. Consequently, the public sector has also shown growing interest during the past decade in facilitating the development of the agricultural sector, best illustrated by the fact that agriculture is explicitly mentioned as a key area of focus in the Sustainable Development Goals. Literature has evidence that suggests how agricultural gross domestic product (GDP) growth has a larger poverty-reducing impact when compared with an equivalent growth in non-agricultural GDP, in the specific context of less developed countries. As the income of a population improves with time, the poverty-reducing effect of the agricultural sector tends to decrease, while that of the non-agricultural sector increases (FAO, 2012). This evidence has led to renewed interest on the part of the public sector in designing a mix of multi-sectoral policies to reduce poverty, in which the development of the agricultural sector plays a key role.

However, the developing agribusiness environment in many rural areas of the world contrasts significantly with the limited role that the formal financial sector has played in providing services to rural areas and to the agricultural sector. Recent studies demonstrate that rural financial markets in developing countries are being dominated by actors who are not part of the formal financial sector.(Hernández, 2017). Agricultural financial markets, in particular, tend to be dominated by actors involved in different segments of the 
agricultural value chains, whose main line of business is not related to finance. Nevertheless, they provide these financial services because they foster improved coordination, stability and loyalty within actors along all segments in the value chain. The capacity of these actors for providing such services stems from the significant informational advantages and lower transaction costs they face when serving a rural clientele in comparison with their formal finance counterparts (Hernández, 2017).

According to Hernández (2017), these various financial service providers outside of the formal financial sector have played a crucial role in allowing an effective supply response to the growing demand for agricultural products. Nevertheless, there is evidence that the equilibrium reached within rural and agricultural financial markets is sub-optimal from a social perspective, given limitations in the outreach, variety, flexibility and costs of the financial products offered, resulting in inadequate coverage and the exclusion of an important part of the rural population, the segment that carries a genuine demand for different financial services.

As a result of limited formal financial services to the rural agricultural farmers, research done in Viet Nam, China, India and the Philippines indicates growing innovative strategies that different rural agents mainly in the agricultural sector have designed in order to make available several financial products that enable agricultural investments throughout value chains. In the process, they have partnered with formal financial institutions, government agencies, and other private enterprises to deal with the several constraints and risks that they face. Even as the informal financial service providers try to cover the inadequate financial service provision to rural agricultural players, the question is as to why the formal financial providers are unable to effectively serve this segment of the population.

Research has shown that agricultural GDP growth has a larger poverty-reducing impact when compared with an equivalent growth in non-agricultural GDP in the specific context of less developed countries (Hernández, 2017). Thus, a more efficient provision of financial services could play an essential role in overcoming these obstacles that rural farmers face in a bid to finance their agricultural projects (Guizar, Gonzalez-Vega and Miranda, 2015).

However, in the processes of financial deepening in low-income countries, lags prevail in the provision of services in the rural areas, particularly in the supply of the financial services required for agricultural activities and of those demanded by households that earn an important portion of their incomes from crops (Hernández, 2017). Part of the problem has been that the process of provision of financial services faces obstacles which are challenging to overcome, in part due to a widespread incidence of market failure (Jaffee and Stiglitz, 1990).

Consequently, this study is designed to examine factors affecting financing of rural agricultural projects in Rwanda with a focus on the experience of Equity Bank.

\section{Literature}

The Asian Development Bank (ADB) (2000) defines microfinance as the provision of a broad range of financial services such as deposits, credits, payment services to the poor and low income households and their microenterprises. The term is often used more narrowly to refer to loans and other services from providers that identify themselves as "microfinance institutions" (MFIs). These institutions commonly tend to use new methods developed over the last 30 years to deliver very small loans to unsalaried borrowers, while asking for little or no collateral. These methods include group lending and liability, pre-loan savings requirements, gradually increasing loan sizes, and an implicit guarantee of ready access to future loans if present loans are repaid fully and promptly.

In a broader perspective, microfinance refers to a movement that envisions a world in which low-income households have permanent access to a range of high quality and affordable financial services offered by a range of retail providers to finance income-producing activities, build assets, stabilize consumption, and protect against risks. These services include but are not limited to savings, credit, insurance, remittances, and payments, and others.

According to Onumah\&Meijerink (2012), lack of finance limits smallholder farmers' productivity and income growth. They acknowledge that access to finance remains a major challenge for smallholder farmers in most developing countries. The problem often is seen in terms of limited access to production credit to buy and use farm inputs as well as pay for non-family farm labour and other farm maintenance costs. Because smallholder farmers cannot afford yield-enhancing inputs, farm productivity often remains low on smallholder farms despite available technology for achieving higher yields (Onumah\&Meijerink, 2012. 
Other than the foregoing, smallholder farmers also face major difficulty in accessing post-harvest credit, often leading to severe household liquidity constraints which often compel them to sell the bulk of their produce at harvest when prices are extremely low. Moreover, financial constraints also prevent them to condition produce to meet quality requirements in premium markets. This way they miss out on opportunities for higher household income. Furthermore, smallholders have limited ac-cess to formal savings facilities because there are few financial institutions that provide such services in rural communities. Consequently, smallholders tend to hold their wealth in non-liquid assets (e.g. livestock and household goods), risking loss through theft, fire or other perils. Insurance and price hedging instruments are almost non-existent because markets for these are missing or severely underdeveloped (Onumah\&Meijerink, 2012) The foregoing reviews of some of the advances being made in developing countries to address financing constraints in the rural agricultural sector by identifying financial models that improve access to financial services to smallholders. It focuses particularly on sustainable models that are embedded in enduring transaction-based relations in agricultural value chains

Across the world, smallholder farmers, who tend to be perceived as high risk, are often excluded from the credit market because of a number of reasons. Their household income is uncertain because of variability in output, which in turn is due to variation in the weather, which is becoming more acute as a result of climate change. Farm production is also affected by diseases, pests and other natural factors. Most smallholder farmers in developing countries are not able to insure themselves against these risks. Nor can they access effective instruments to hedge price risks to which they are highly vulnerable as a result of inefficiencies in marketing systems and/or ad hoc policy interventions. This has had the effect of leaving rural agricultural farmers highly vulnerable.

Moreover, due to low per capita rural income, most smallholders do not meet the minimum equity contributions that financial intermediaries require from borrowers. Furthermore, smallholders usually lack assets considered as suitable collateral by financial intermediaries. In addition, factors such as high administration costs - because smallholders farmers are small and widely dispersed - poor and costly contract enforcement and acute information asymmetry problems further make smallholder farmers unattractive to formal financial intermediaries (Onumah\&Meijerink, 2012)

The microfinance theory has been expounded by Hearth (2018). In defining microfinance, Hearth (2018) adopts the definition by The Asian Development Bank (ADB) (2000) which sees microfinance as the provision of a broad range of financial services such as deposits, credits, payment services to the poor and low income households and their microenterprises. According to Hearth (2018), the theory of microfinance considers microfinance to be an entry point in a wider strategy for enlarging poor's lively-hood options. Microfinance services can be categorized as follows:

Micro-credit: They offer a reliable source of working capital, dispersed against 'collateral substitutes' such as standing in the community, group guarantees or compulsory savings.

Deposit services: They are designed to offer poor households alternative savings options to the hoarding of cash or other stores of value.

Insurance products: They include insurance against loan default due to misadventure, illness, death, natural disasters or unanticipated economic crisis, plus anticipated life-cycle related savings goals to prepare for weddings, funerals or other socio-economic obligations.

Financial advisory services: They relate to situations whereby the views and needs of the poor are given a voice and brought to the attention of policy makers, regulators and those with the authority to influence the environment in which poor households and informal sector institutions have to operate.

According to Hearth (2018), MFIs be they a bank, a cooperative, a credit union, an NGO or some other form of non-bank financial intermediary, seek to provide clients or low income households with a range of money management and banking services. Microfinance appeared as a strategy to address the institutionalized exclusion of the poor, especially women, from formal financial systems. Microfinance is considered as a tool for poverty and vulnerability reduction based on the premise that improved access to credit by the poor is crucial to improve the returns to economic activities; it expands self-employment and promotes business and entrepreneurial activities; it allows incomes to grow and provides a "safety net" to the poor who are vulnerable to income fluctuations.

Hearth (2018) notes that the existing evidence on the impact of microfinance on poverty and vulnerability reduction of poor is ambiguous. While some research work suggests that access to microfinance has the 
potential to reduce poverty significantly; others argue that microfinance has a minimal impact on poverty reduction. To illustrate this, Hearth (2018) says that studies like that of Daley-Harris and Zimmerman (2009) show that when microfinance is used to meet day-to-day consumption it can lead to debt for the borrowers. This theory will help to explain how microfinance is helping the poor to access credit and the challenges that are involved.

\section{Empirical Review}

Several studies about the challenges of financing rural agricultural projects and how to address the challenges have been reviewed including studies from Viet Nam, India, China, the Philippines. Innovations in financing rural agricultural projects have been explored. The studied cases recognize how these innovative business models enable the provision of credit, savings, insurance and payments services to the rural population and facilitate investments in the agricultural sector. It presents some evidence that these business models have been more inclusive of poorer rural households dependent on agriculture, which constitute a significant share of those financially excluded around the world (Hernández, 2017). The cases documented pro-vide some important policy lessons that aim to effectively promote more inclusive rural financial markets.

Research on India illustrates how some commercial banks have invested in acquiring knowledge about domestic agricultural markets to identify those unmet financial needs they can serve. In this case the identified needs relate to agricultural payments and savings required by rural actors such as small-scale milk producers and dairy processors. The strategy used to cater this clientele segment leverages on digital technology in order to ensure these services are more convenient to clients, in addition to having low operation costs. The experiences illustrated show how digital technology can be tailored to fit very unique transactions that take place in agricultural value chain segments, and these payment systems can have significant scale. In addition, they enable the recording of a transaction history, which can be used for the development of additional rural financial services (Hernández, 2017).

About the Philippines shows how pioneer microfinance institutions have been able to transform traditional microfinance methodologies, which have typically fitted mainly the urban poor with small loans requiring monthly repayments, with agricultural finance methodology that require bulkier loans with repayments schedules fitting the longer-term agricultural calendar. The new methodology has enabled these financial institutions to cater the largely unmet agricultural financing needs among poor rural households. In addition, in order to reduce costs and manage risks better, these financial institutions have partnered with agribusiness firms and government agencies that can provide clients with services that mitigate production, market, and climatic risks. These organizations benefit from the partnership as they secure agricultural products for their industries and they achieve more effectively their rural development goals (Hernández, 2017).

For the case of China, the study highlights how some private technology companies that do not form part of the formal financial sector, have recognized the enormous business potential that providing financial services to poorer rural households represents, especially considering how this clientele segment seems to be underserved by formal financial institutions. Taking advantage of the massive data these firms have accumulated on individuals' transactions, they have been able to develop a lending methodology based on scoring systems that does not require any collateral and is able to assess creditworthiness based on the client characteristics. Given the uniqueness of rural livelihoods and their relative low presence in big data sets, this methodology does not only rely on scoring algorithms, but also on partnerships with local government agencies and other rural actors that can provide additional client information, which was recognized as critical for an adequate loan underwriting process. The result has been the formation of a massive rural credit portfolio during a very short amount of time.

The case of Viet Nam shows how small and medium agribusiness firms can pro-vide financial services to poor rural households that are underserved by the formal financial sector, including development banks that specifically target this clientele segment but fail to achieve the necessary scale. These agribusinesses make efforts to provide these services because they allow to secure the agricultural production they need for their trading or processing activities. The analysis presented shows how public programs - once they recognize and value the significant informational advantages that these small and medium agribusiness have on smallholder families' needs and local agricultural market dynamics - can promote successful partnerships 
between formal financial institutions and these agribusinesses to enable the provision of financial services to poorer rural households. This win-win arrangement enables the rural portfolio of formal financial institutions to reach greater scale, diversifying the types of financial products offered and the clientele segments reached composed of smallholder families and various rural businesses along agricultural value chain segments, thereby exploiting economies of scope and scale.

The foregoing literature is illustrative of how policies that aim to promote rural financial inclusion can be more effective when they focus on promoting a merger of capacities and knowledge between formal financial institutions and rural economic actors. According to Hernández (2017), an ideal policy goal would be to promote a mix of public interventions that, by promoting this merger of capacities and knowledge, facilitate a process of innovation within the financial sector in order to define new products and internal processes that lower costs and improve the ability to assess client needs, manage risks, and develop a rural portfolio that is fully financially self-sustaining.

\section{Methodology}

This study adopted a descriptive cross-sectional research design. Descriptive research design is relevant in describing the study variables as they are, while the cross-sectional design is about studying variables at a particular point in time.

The entire population of this study consisted of 450 people. These were farmers in Musanze District that Equity Bank is closely working with to finance their agricultural ventures.

A sample is a subset of the population. According to Teddlie\&Tashakkori (2009), it comprises some members selected from the population. In this study, the sample size consisted of 211 respondents selected using the formula shown below.

$$
\frac{N}{1+N(e)^{2}}
$$

The sample size is calculated at $95 \%$ confidence level, an alpha level of 0.05 which is margin of error of $\pm 5 \%$ and 0.5 as the standard deviation which shows how much variance expects in as responses.

$\mathrm{n}=450 / 1+450(0.05 \times 0.05)$

$\mathrm{n}=211$

Sampling techniques provides a variety of different methods that allows the researcher to lessen the total quantity of data desired to be collected by taking into account only data from a sub-group rather than all possible cases (Saunders (2007). For this study, sampling was done by applying the simple random sampling technique.

For this study, data was sourced by two main approaches. Primary data collected by use of questionnaires, interview and observation in the field; while secondary data was obtained from documented sources including books, journal articles, websites, reports, among others.

Several methods were relied upon for collection of data,

\section{Document review}

The researcher collected secondary data from different sources including textbooks, internet, newspaper, magazines, journals and reports.

\section{Questionnaires}

The researcher developed open-ended questions as well as close-ended questions that constituted the entire questionnaire. The researcher dropped the questionnaires; gave them out to respondents two days to respond. Thereafter, the researcher then collected the filled questionnaires.

\section{Interviews}

A set of open-ended questions were structured to get further data for this study. Interviews are useful for gaining insight and context into a subject, allowed respondents to describe what is important to them and also useful for gathering verbatim data. Interviews were conducted with key informants who had information about the variables under study.

\section{Observation}


Observation involves the viewing and recording relevant information about the phenomena that is under study. This method was applied in this study to help in the triangulation of other methods as foretasted.

\section{Data Collection Instruments}

The study relied on various tools in the process of data collection in a bid to come up with sound, concrete and credible findings. The researcher therefore applied the following tools:

\section{Document review checklist}

A document review checklist was applied to help in systematic review of all the relevant documents.

\section{Questionnaire}

Questionnaires with both open and closed-ended items were developed and used to collect data.

\section{Interview guide}

An interview guide with a set of questions that were used during the exercise of interviewing the respondents

\section{Observation Schedule}

This was used to make observations about nature and size of projects, project location, and even what is grown by the farmers.

\section{Findings, Discussion and Interpretation}

The research basically considered a survey research design, questionnaire and interview in collecting or gathering data while SPSS was purely relied on while analysing data. The major objective of this study centralised around the factor that affects rural agricultural projects on financial accessibility particularly from the equity Equity bank experiences, the specific objectives were to find out how financing activities affects the rural agricultural projects MUSANZE DISTRICT, to establish the effect of financial services on agricultural projects in Musanze District and to show how financing activities affect the rural agricultural projects in Musanze District.

The first objective of this study was to assess how nature of existing financial products by Equity Bank influences financing of rural agricultural project in Rwanda.

Basing on the respondents views on their level of agreement to the statements relate to rural agricultural projects for most farmers are small in MUSANZE DISTRICT, it was revealed that $32.8 \%$ strongly agree that Musanze district Rural agricultural projects for most farmers are small, 52.8\% agree with the statement and $14.2 \%$ disagree Musanze district 4.84 and a standard deviation of 0.42 .

In relation to the statement intended to know whether Musanze district rural agricultural projects for most farmers are small with mean of not much profit is generated from sale of the farming proceeds, $42.2 \%$ of total respondents strongly agree with the statement, $42.8 \%$ agree with the statement and $14.2 \%$ disagree with the statement. With a mean of 4.67 and standard deviation of 0.45 . In this research $45.7 \%$ of total respondents strongly agree that in Musanze district not much profit is generated from sale of the farming proceeds and $52.0 \%$ of total respondents agree with the statement with a mean of 4.82 and standard deviation of 0.42

Finally, $18.5 \%$ of total respondents strongly agree that in Musanze district lack of adequate land is a limiting factor to rural agriculture regarding financial support $60.0 \%$ of total respondents agree with the statement and $7.1 \%$ disagree with the statement with a mean of 4.32 and standard deviation of 0.47 . From the findings in table 4.6, most of respondents agree with the statement relate to the lack of adequate land is a limiting factor to rural agriculture regarding the financial services and this is supported by the fact that all means of their responses are at very high range which indicate the existence of financial support in Musanze district.

The second objective was to Examine how Nature Of Rural Agricultural Projects in Rwanda Influence Access To Equity Bank's Financial Services.

Concerning the second objective of this research which was analysis of the contribution of employees empowerment on employees' retention in Musanze District, From the table4.6, researcher asked the 
respondents to give their level of agreement to the statements relate to the employees' empowerment as a factor of capacity building in MUSANZE DISTRICT, it was revealed that $32.8 \%$ strongly agree that Musanzedistrict encourages employee empowerment and self-initiative, 52.8\% agree with the statement and $14.2 \%$ disagree Musanzedistrict encourages employee empowerment and self-initiative with mean of 4.84 and a standard deviation of 0.42 .

In relation to the statement intended to know whether Musanzedistrict increase employee self-efficacy need for the betterment of organization, $42.2 \%$ of total respondents strongly agree with the statement, $42.8 \%$ agree with the statement and $14.2 \%$ disagree with the statement. with a mean of 4.67 and standard deviation of 0.45 . In this research $45.7 \%$ of total respondents strongly agree that in Musanze district the work is given with respect to employees' ideas and $52.0 \%$ of total respondents agree with the statement with a mean of 4.82 and standard deviation of 0.42

The third objective of this study was to Assess How Characteristics of Rural Clients Who Engage in Agricultural Projects in Rwanda Influence their Ability to Access Equity Bank's Financial Services.

The third objective of this research was the assessment of the contribution of ability to access on financial services, As pointed out by the respondents in table 4.9 in relation in relation to perception of respondents on perception of respondents on characteristics of rural farmers who Engage in Agricultural Projects in MUSANZE DISTRICT, 32.8\% of the total respondents strongly agree that they get Self-awareness through the Perception of respondents on Characteristics of Rural Farmers who Engage in Agricultural Projects, $67.1 \%$ of total respondents agree with the statement with a mean 4.80 and standard deviation of 0.40 , regarding the statement which is says that Most rural farmers depend on the produce for a living, $61.4 \%$ of total respondents strongly agree with the statement and 38.5\% agree with the statement, with a mean of 4.16 and standard deviation of 0.36 . When it come to the statement which said that most rural farmers do not have collateral for loan purposes, $55.7 \%$ of total respondents strongly agree with the statement and $44.2 \%$ of total respondents agree with the statement with a mean of 4.86 and standard deviation of 0.45 .

Lastly, $80.0 \%$ of total respondents strongly agree that most rural farmers are poor and $20.0 \%$ of the total respondents agree with the statement with a mean of 4.67 and standard deviation of 0.48 . From the findings in table 4.7, most of respondents agree with the statement relate to the most rural farmers are poor in Musanze District as financial institutions his is supported by the fact that all means of their responses are at very high range which indicate the most rural farmers are poor in Musanze District

The fourth objective was to examine influence of how rural agricultural environment in Rwanda influences ability of farmers to access Equity Bank's financial services.

As pointed out by the respondents in table4.10 in relation to their level the effect of rural agricultural environment, $78.5 \%$ of total respondents strongly agree that tMost rural areas are not well connected by road in Musanze District and $21.4 \%$ of the total respondents agree the statement with a mean of 4.41 and standard deviation of $0.37 ; 47.1 \%$ of total respondents strongly agree that Some of the rural roads are not passable especially during rainy season in Musanze district and 52.8\% of total respondents agree with the statement with a mean of 4.16 and standard deviation of 0.36 . In this research, $41.4 \%$ of total respondents strongly agree that lack of adequate land for farming is a major problemMusanze district and $58.2 \%$ of total respondents agree with the statement with a mean of 4.45 and standard deviation of 0.30 .

In relation to the statement on Most of the rural areas are too hilly in Musanze district,45.7\% of total respondents strongly agree with the statement and 54.2\% agree with the statement with a mean of 4.53 and standard deviation of 0.42 . Lastly, $35.7 \%$ of total respondents strongly agree that most of the rural areas are infertile of Musanze district affect the financial support, $50.0 \%$ of total respondents agree with the statement and $14.2 \%$ of total respondents remained undecided with a mean of 4.09 and standard deviation of 0.49. From the findings in table 4.8, most of respondents agree with the statement relate to the effect of Most of the rural areas are infertile and this is supported by the fact that all means of their responses are at very high range which indicate the existence of effect Most of the rural areas are infertile in Musanze District.

\section{Conclusion}

Considering the findings in this research, it is extremely important for the researcher to conclude that Musanze district perceives financial support the project as indicated by a huge response in agreement with the statements that are related to the financial assistance.it also been indicated that for the farmers in rural 
areas to successfully be able to make the best from the projects, they ought to consider relying on the financial support from financial institutions, as all hypothesis in the research confirmed.

\section{Suggestions To Musanze District}

From on the shortcomings of the research, MUSANZE DISTRICT is suggested to provide a clear environment for financial institutions to get into the area whenever its necessary because a number of respondents disagreed with this statement and the institution also is suggested to have a smooth environment with to create an environment among its communities,

The researcher suggests MUSANZE DISTRICT to improve the farmer's empowerment as fact of financial services because some respondents disagree with the statement relate to receiving adequate and reliable financial support.

\section{Suggestion On Further Research}

Just as it has been clearly seen in the review of literature, there is a limited amount of research done on the financing rural agricultural projects and their accessibility to the financial support from banking sectors for instance Equity bank in Rwanda. Thus the findings and conclusions in this study serves as a basis for the current and future studies within this very line of rural agricultural financing project and financial accessibility.

Financial managers of the respective financial institution at large mainly in equity had not been widely got informed about this existing gap in African particularly Rwandan contexts. This very study therefor, contributes to the knowledge by establishing the fact that financial rural agricultural projects affects the accessibility of financial support from equity bank, something that calls further research to be done considering other factors that influence the financial support from financial banks.

\section{References}

1. Amin, M.E. (2005). Social science research conception, methodology and analysis. Kampala: Makerere University Press.

2. Asian Development Bank (ADB) (2000) Finance for the Poor. Microfinance Development Strategy, Manila.

3. Daley-Harris, S. and Zimmerman, J. (2009) Microfinance Does Not Usually Serve the Very Poor, for Whom It Can Represent a Route into Debt Rather than a Way out of Poverty. EnterpriseDevelopment and Microfinance 20(2): 79-85.

4. FAO (2012).The state of food and agriculture 2012: Investing in agriculture for a betterfuture. FAO, Rome.

5. Guízar, I., Gonzalez-Vega, C. \& Miranda, M. (2015).Uneven Influence of Credit andSavings Deposits on the Dynamics of Technology Decisions and Poverty Traps. PhDDissertation, Department of Agricultural Economics. The Ohio State University. USA.

6. Hearth, H.M.W.A. (2018).Microfinance: Theory and Practice. Colombo: S. Godage\& Brothers (Pvt) Ltd.

7. Hernández, E. (ed.), (2017). Innovative risk management strategies in rural and agriculture finance -The Asian experience.Rome, Italy: FAO

8. Onumah, G.\&Meijerink, G.W. (2012) Innovative Agricultural Financing Models.Accessed on $20^{\text {th }}$ March, 2020 from https://www.researchgate.net/publication/283418691

9. Tedlie, C., \&Tashakori, A. (2009). Foundations of Mixed Methods Research: Integrating Quantitative and Qualitative Approaches in the Social and Behavioral Sciences. Thousand oaks: Sage Publications Inc.

10. Wilson, (2012).Methodology and techniques for data collection, USA: Kentler Publishing Company 